\title{
Concepciones epistemológicas del docente y su incidencia en la enseñanza de las
} ciencias*

\author{
María Aiello ${ }^{1}$
}

\begin{abstract}
Resumen
Este trabajo tiene como objetivos: a) indagar las creencias de los docentes con relación a la naturaleza de la ciencia y b) conocer hasta qué punto su práctica es coherente con la epistemología que sustentan. Se trabajó con una muestra no probabilística, constituida por 20 docentes de nivel medio de la ciudad de San Luis (Argentina). Los datos obtenidos muestran que, en general, los docentes sustentan una concepción de ciencia superadora del enfoque positivista y que intenta aproximarse a lo que es la práctica real de los científicos. Sin embargo, existen ciertas contradicciones en las notas distintivas que configuran dicha concepción. Respecto a su intervención en la práctica del aula, algunas actividades resultan acordes con una postura constructivista, en tanto que otras, reflejan los vestigios de una tradición positivista fuertemente arraigada en ellos. En cuanto al grado de coherencia entre la práctica y la epistemología que sustenta el docente, los coeficientes obtenidos, si bien son de intensidad baja y moderada, indican que, en general, el modo de enseñar ciencia y de evaluar a los alumnos no resulta totalmente coherente con la concepción de conocimiento científico que poseen los docentes.
\end{abstract}

Palabras clave: Concepciones epistemológicas, enseñanza, ciencias

\section{Summary}

This work is aimed at investigating: a) teacher's beliefs about the nature of science and b) whether their teaching practices are coherent to the epistemological approach they hold. This work war carried out on a non-probabilistic sample made up of 20 high school teachers from San Luis City (Argentina). The data obtained show that, in general, teachers hold a conception of science, which surpasses the positivist viewpoint, and they attempt to resemble scientists' actual practices. However, there are certain contradictions in the distinctive features of such conception. With respect to teachers' classroom practices, some activities are consistent with the constructivist approach, while others reflect the remnants of a deeply-rooted positivist tradition. As regard the degree of coherence between teachers' practices and the epistemological approach that they adhere to, the coefficients obtained, although they have a low and moderate intensity, show that, in general, the way teachers teach science and evaluate students is not completely consistent with the conception of scientific knowledge that teachers hold.

Key words: Epistemological conceptions, teaching, sciences

\footnotetext{
* Texto recibido el 21 de agosto de 2003 y arbitrado el 4 de mayo de 2004.

1 Profesora asociada del área de metodología de la investigación del Departamento de Educación y Formación Docente de la Facultad de Ciencias Humanas de la Universidad Nacional de San Luis, Argentina. Profesora de enseñanza secundaria, normal y especial en pedagogía. Codirectora de tesis de la licenciatura en Ciencias de la Educación. Especialista en Didáctica. Asesora metodológica de planes y tesis de licenciatura en Ciencias de la Educación. E-mail: maiello@unsl.edu.ar.
} 


\section{Marco teórico}

En las prácticas pedagógicas cotidianas del docente subyacen diversas concepciones, algunas de las cuales resultan determinantes para el análisis y la explicación de los fundamentos de sus propuestas didácticas. Entre las más relevantes hay que mencionar las concepciones acerca del aprendizaje, del sujeto que aprende, de la ciencia y el conocimiento, del sujeto que enseña, etc.

A menudo nos encontramos con prácticas que dan cuenta de cierta coherencia entre estas concepciones y que están sustentadas en ellas. En ocasiones, sin embargo pueden observarse contradicciones e incoherencias que se justifican de diferente modo. Las concepciones epistemológicas del docente están presentes en la toma de decisiones en relación con los distintos componentes del currículum, por lo que tienen una proyección en la práctica.

Young afirma que "muchos profesores -sobre todo en la enseñanza secundaria- poseen una cierta idea, aunque sea genérica, acerca de lo que es el conocimiento, que puede jugar un papel importante en la organización más concreta de las creencias y decisiones sobre el conocimiento en la enseñanza y en el proceso de aprendizaje" (1981: 216).

Las consideraciones en torno al conocimiento que poseen los docentes son elaboraciones personales configuradas en el trayecto de su formación y a través de la experiencia, que se movilizan y adquieren vigencia en el momento de adoptar decisiones para su intervención en la práctica del aula. Estas distintas posturas epistemológicas, que muchas veces están escasamente fundamentadas en el análisis histórico y filosófico, implican una práctica educativa diferente. En este sentido, los cursos de historia y filosofía de la ciencia pueden contribuir a que el profesor logre una mejor comprensión de los contenidos científicos y desarrolle una epistemología de la ciencia más auténtica y real.

Dos son los componentes que se suelen distinguir en la formación del profesor: la formación básica, es decir, cierto dominio del conocimiento por impartir, y la formación pedagógica. Cuando el docente transmite un contenido, produce una transformación de ese conocimiento a fin de posibilitar la comprensión del alumno. La transmisión del conocimiento científico en la escuela es un tema de gran interés y que requiere especial atención. Boido expresa al respecto: "El carácter ahistórico que suele tener la enseñanza de la ciencia es pernicioso, porque... se corre el riesgo de ofrecer una imagen desnaturalizada del quehacer científico y de la ciencia misma" (1985).

El problema de la transmisión del conocimiento científico en la escuela implica el análisis de la práctica docente, la cual se configura en el interjuego de tres elementos: docentealumno-conocimiento. Esto plantea el problema de la transposición que Chevallard denomina didáctica; es decir, las modificaciones que sufre un objeto de conocimiento cuando es objeto de enseñanza. Una visión absolutista y dogmática del conocimiento científico dará lugar a una enseñanza basada en la transmisión de conocimientos como verdades definitivas e incuestionables.

Las concepciones sobre la naturaleza de la ciencia que transmiten frecuentemente los libros escolares o manuales resultan muchas veces totalmente distorsionadas y alejadas de la realidad. Muestran la imagen del científico como un genio en una torre de marfil, y el conocimiento aparece desvinculado del contexto histórico y social que lo hizo posible.

Como se dijo anteriormente, las posiciones epistemológicas del docente están presentes, en alguna medida, en el modo en que se lleva a cabo la enseñanza. Pope y Scott destacan la importancia de haber descubierto que 
la concepción positivista, empirista-inductivista de la ciencia, está en relación con una visión absolutista del conocimiento y, que, en ese caso, los contenidos del curriculum y la forma de enseñar a los alumnos prestan poca atención a las concepciones de los estudiantes y a su participación activa (1984: 217).

Una postura relativista del conocimiento, en cambio, resulta coherente con actitudes de aceptación ante los errores de los alumnos, de estimulación hacia la búsqueda de soluciones alternativas y divergentes de propuestas de trabajo con base en interrogantes y no en certezas, etc.

\section{Concepción clásica de la ciencia}

La concepción clásica de la ciencia tiene su génesis en filósofos que han pertenecido al Círculo de Viena o que han influido de alguna manera en él. La visión cientificista, inductivista y empirista de la ciencia se origina en la corriente positivista del siglo pasado y encierra los supuestos que sustentó el neopositivismo. Algunos de estos supuestos se enuncian a continuación:

a) La existencia de un solo método para todas las ciencias, en el que se establecen un conjunto de pasos y reglas, cuyo cumplimiento garantiza el arribo a la verdad.

b) El reconocimiento de la explicación causal que caracteriza a las ciencias naturales como el único objetivo válido de la ciencia. Las investigaciones, caracterizadas como nomotéticas, buscan explicar los fenómenos a través de leyes causales. Para ello es necesario reducir un fenómeno complejo a sus partes integrantes, para su estudio individual y en forma aislada.

c) La visión empirista de la observación como base del conocimiento científico.

d) La lógica inductiva. La ciencia asciende inductivamente de lo observable, del mundo inmediato de los hechos, hasta la teoría.

e) La mente del científico es considerada una tábula rasa, libre de teorías o ideas previas, como expresaba Bacon.

f) Las teorías científicas son una copia de la realidad. El conocimiento es un reflejo en el sujeto, de algo que está allí fuera (el objeto). El investigador no interfiere en absoluto con su objeto de estudio.

g) El progreso de la ciencia es continuo. La ciencia tiene un carácter progresivo, avanza por acumulación de verdades objetivas, verificadas, ciertas y definitivas sobre la naturaleza.

h) La neutralidad axiológica del investigador debida a la escisión entre valores y hechos.

i) La autonomía del quehacer científico respecto al contexto histórico y social y al poder político y económico.

\section{Implicaciones en lo educativo}

La epistemología positivista penetró en el ámbito de la pedagogía y de la didáctica bajo la expresión de un modelo de racionalidad técnica. La racionalidad técnica reduce la intervención del docente a la selección y aplicación de los medios adecuados para alcanzar objetivos previamente establecidos. Desde esta perspectiva, los problemas que debe resolver el docente son de tipo instrumental, descuidando la faceta moral y política de los fines que están presentes en toda práctica educativa. Las normas de intervención del docente en el aula provienen del resultado de estudios científicos en los que se establecen relaciones entre la actuación del docente y el rendimiento de los alumnos. 
La intervención técnica utiliza principios genéricos válidos para cualquier circunstancia y cualquier grupo de alumnos. Parte del supuesto de la homogeneidad de los grupos de clase, cuando en realidad las diferencias culturales y sociales de los alumnos contradicen dicho supuesto.

Si se tienen en cuenta las características de la práctica educativa: "complejidad, incertidumbre, inestabilidad, singularidad y conflicto de valores" (Gimeno y Pérez, 1995: 97), resulta imposible prever, en función de la multiplicidad de variables en juego, lo que ocurrirá en el aula en cada situación particular, razón por la cual la actuación basada en los parámetros de la racionalidad técnica resulta inadecuada. El docente no puede resolver situaciones en el aula aplicando recetas disponibles porque cada situación es única, singular y por tanto requiere soluciones específicas.

Los principios de una epistemología positivista subyacen a la denominada pedagogía por objetivos.

La misión básica de este modelo es tecnificar el proceso educativo sobre bases científicas, sin pretensiones de ser un modelo para entender qué es y cómo cambiar la educación. Su preocupación es técnica, no de discusión teórica e ideológica, cuando, paradójicamente, la crisis fundamental hoy es un problema de cambio de rumbo, un problema de fines tanto o más que un problema técnico (Gimeno, 1995: 10-11).

Desde este paradigma, se debe capacitar al docente para programar y evaluar. En toda programación se deben especificar los objetivos por alcanzar estableciendo su logro en términos de conductas observables. Tyler, el padre del movimiento de los objetivos de conducta expresa que el especificar la conducta que los alumnos deben desarrollar facilita la evaluación de las actividades.

A diferencia de Tyler, Hilda Taba asigna a los objetivos una función amplia y hace énfasis en su adecuación a una sociedad cada vez más compleja. Distingue entre objetivos generales que se logran a largo plazo y objetivos específicos que se logran de modo más inmediato.

Mager, en su libro Formulación operativa de objetivos didácticos, expresa la nece-sidad de formular objetivos operacionales. Los objetivos operacionales debían indicar con precisión los criterios de evaluación. "El objetivo describe un resultado previsto en la enseñanza, más bien que el proceso mismo de la enseñanza" (1980: 5). Los objetivos operacionales debían señalar: lo que el alumno debía hacer, las condiciones y el grado de perfección. "Esta visión reduce la conducta humana a lo observable, las aspiraciones a lo definible, la educación a lo tangible, la técnica pedagógica a una sucesión mecánica de pasos" (Gimeno, 54).

Podría pensarse que con este modelo se superan las deficiencias del docente. Quienes tienen escasa experiencia suelen planificar apoyándose en este modelo, y habitualmente son muy rigurosos al llevar a la práctica lo planificado; de allí que dejen en un plano secundario las características específicas del grupo de alumnos con que trabajan.

Sin embargo, los problemas educativos del momento actual y la necesidad de mejorar la calidad de la educación, exigen del docente, la capacitación para nuevos papeles y funciones, para lo cual este modelo tecnicista de la pedagogía por objetivos resulta inadecuado.

La concepción positivista de ciencia que hemos expuesto da lugar a prácticas en donde se concibe el conocimiento como entidad, donde los conocimientos deben ser parcelados, accediéndose a átomos de conocimiento. Desde esta perspectiva, la evaluación sólo tiene en cuenta los productos obtenidos, dejando de lado los procesos por los que se 
alcanzaron. Se pone énfasis en la capacidad del alumno para retener la información. Los alumnos están "más preocupados por obtener una buena calificación que por autoconocerse, observarse y reflexionar sobre su aprendizaje” (Díaz Barriga, 1991: 123).

\section{Visión post-positivista de la ciencia}

A partir de la década del sesenta del siglo pasado se produce una superación de la epistemología positivista. Utilizando el lenguaje de Kuhn, del mismo modo que las revoluciones científicas producen cambios de paradigmas, también en la filosofía de la ciencia aparece un cambio paradigmático, como alternativa al enfoque analítico del neopositivismo. Las notas distintivas de este nuevo paradigma son:

1. La crítica al inductivismo baconiano (Popper, 1980). Las teorías no son inferidas por vía inductiva, sino que son invenciones de la mente humana, que determinan qué datos se recogen y cómo se interpretan.

2. El rechazo del "método lógico como único método de examen de las teorías científicas. El análisis exclusivamente lógico debía contentarse con los aspectos estáticos de la ciencia, y por ello con descripciones de momentos instantáneos de la ciencia, no pudiendo dar cuenta del desarrollo dinámico de las teorías" (Castorina y Palau, 1994: 18). 3. El ataque a la idea de que la ciencia se basa en la experiencia, pues no hay observaciones ni hechos puros. Los marcos teóricos y conceptuales orientan y condicionan la observación y nuestra interpretación de la realidad. Toda observación tiene una carga teórica.

4. El pluralismo metodológico. No existe consenso en cuanto a lo que es el método científico (Feyerabend, 1975). Hay distintas metodologías que pueden ser aplicadas en función del objeto de estudio y el propósito que se persigue en la investigación.

5. Las teorías no constituyen un reflejo de la realidad. Las teorías son construcciones del sujeto, individual o colectivo, que tratan de reconstruir modélicamente la realidad (Kuhn, 1978; Piaget, 1986). Se destaca el papel activo y la creatividad por parte del sujeto.

6. La objetividad en la ciencia no reside en la concordancia entre el conocimiento obtenido y la cosa conocida, sino en la intersubjetividad entre los miembros de la comunidad científica.

7. La historia de la ciencia no es un proceso acumulativo y lineal. Es un proceso que presenta rupturas y discontinuidades caracterizadas por la aparición de nuevos marcos conceptuales. El cambio científico se realiza a través de nuevos paradigmas (Kuhn, 1978). El tránsito de un paradigma a otro es denominado revolución científica y significa una reestructuración del marco conceptual que sirve de base a la investigación.

8. Las teorías científicas nunca se verifican totalmente. Las teorías son sustituidas por otras más fértiles y que tienen mayor poder explicativo.

9. Las teorías científicas no son infalibles. Todo conocimiento tiene un carácter hipotético, conjetural, provisional. El quehacer científico puede ser sometido a la crítica y a la autocorrección.

10. La no neutralidad de la ciencia. Las ideas, creencias y los valores que son inherentes al ser humano, y de los cuales no puede despojarse, influyen en la actividad cognoscitiva científica.

11. La concepción clásica daba la imagen de que la ciencia se producía en un vacío social, desvinculada de la práctica real de los científicos. El nuevo paradigma, en cambio, concibe la ciencia como una construcción social en un determinado contexto histórico. 
12. La reflexión epistemológica no se centra en enunciados científicos y sus relaciones lógicas, sino en aspectos tales como los paradigmas de Kuhn, los programas de investigación de Lakatos, etc.

Esta visión post-positivista de la ciencia supone una epistemología constructivista, al considerarla como una construcción social realizada históricamente por la comunidad científica. La epistemología constructivista -que tiene a Piaget como una de sus principales figuras-, destaca el papel activo del sujeto en su relación con el objeto. Esta epistemología constructivista es la base de la concepción constructivista de la enseñanza y del aprendizaje de la ciencia.

\section{Implicaciones en lo educativo}

Dentro de esta perspectiva constructivista del aprendizaje, se encuadra el enfoque de las concepciones alternativas, ideas previas o teorías implícitas de los alumnos en la enseñanza de las ciencias naturales.

Estas ideas previas o teorías personales de los estudiantes en relación con la enseñanza de la ciencia, si bien suelen tener a veces gran riqueza, frecuentemente resultan limitadas y erróneas, por lo que entran en conflicto con lo que se enseña en el ámbito de la escuela. Estas teorías personales, construidas con base en la propia experiencia, son los instrumentos cognitivos del alumno para comprender la realidad, por lo que adquieren tal significación y están arraigadas de tal modo que son resistentes al cambio y difíciles de erradicar. El alumno se debe enfrentar en su aprendizaje al difícil proceso de cambio conceptual, entendido como el proceso por el cual se modifican las concepciones espontáneas o teorías personales de los alumnos por conceptos científicos, estableciendo conexiones adecuadas entre ellos.

Un papel decisivo en este proceso tiene la denominada ecología conceptual (Toulmin, 1972).

La ecología conceptual está constituida por las creencias, los conceptos existentes, erróneos y adecuados, que forman parte de la estructura de conocimiento del sujeto. Tiene una gran influencia en el proceso de cambio conceptual, tanto por la generación de la necesidad de cambio, como por la dirección que tomará éste (Carretero, 1996: 66).

Algunos autores consideran el cambio conceptual como un proceso de dos fases, utilizando la terminología piagetiana. Una primera fase de asimilación es aquella en la cual la nueva información se interpreta en términos de la estructura de conocimiento que posee el sujeto. Sin embargo, a veces dicha estructura es insuficiente para interpretar un nuevo fenómeno; se hace necesario entonces modificarla, remplazando y reorganizando los conceptos centrales de la teoría del sujeto, para poder explicar ese nuevo fenómeno. Esta segunda fase es la fase denominada de acomodación.

Desde la perspectiva del cambio conceptual, reviste especial importancia la elaboración por parte del docente de sus propios instrumentos para indagar y hacer explícitas las ideas espontáneas de los alumnos. La identificación de estas ideas suele presentar dificultades debido a que muchas veces se trata de ideas que carecen de un alto grado de coherencia y son de estabilidad variable.

Una vez que estas ideas han sido identificadas, y se ha comprobado que son erróneas, se deben poner en práctica estrategias que promuevan el cambio conceptual. Para cambiar estas ideas, el docente debe: 
a) Generar situaciones en donde los alumnos puedan convencerse de que las ideas que poseen y consideran válidas para explicar la realidad resultan insatisfactorias. La puesta en cuestión de las ideas de los estudiantes se puede realizar a través del uso de contraejemplos.

b) Presentar una concepción alternativa a la concepción errónea del alumno. El alumno debe tomar conciencia de que esta nueva concepción permite resolver los problemas y explicar la realidad, superando los inconvenientes que planteaba su teoría personal y de modo más satisfactorio.

Sustentada en esta concepción constructivista del aprendizaje, la evaluación es considerada un proceso orientado a la comprensión de las dificultades y los logros del alumno. Es un proceso continuo, cualitativo, que lleva al estudiante a la toma de conciencia de sus propios procesos de aprendizaje.

Se tienen en cuenta tanto los aprendizajes alcanzados como el camino seguido en su adquisición; esto permite realizar ajustes sobre la marcha del proceso. Los instrumentos de evaluación acordes con esta concepción deben reunir básicamente los siguientes requisitos: a) ser abiertos, a fin de que permitan evaluar procesos complejos y no solamente memoria; b) flexibles, para que puedan ajustarse a situaciones particulares; c) dinámicos, a fin de que puedan captar todos los aspectos vinculados a la evolución del proceso, d) globalizadores, de modo que posibiliten la integración y transferencia de aprendizajes significativos.

\section{Objetivos}

Indagar las creencias de los docentes en relación con la naturaleza de la ciencia (epistemología del docente).

Conocer hasta qué punto la práctica del docente es coherente con la epistemología que sustenta.

\section{Metodología}

\section{Muestra}

Se trabajó con una muestra no probabilística, de tipo accidental, constituida por 20 docentes de nivel medio de la ciudad capital de la provincia de San Luis. Es en este nivel donde los contenidos científicos adquieren mayor importancia, destacandose lo conceptual en el ámbito de cada disciplina. Del total de docentes de la muestra, quince eran de sexo femenino y cinco de sexo masculino, y desempeñaban su labor en el área de Ciencias Naturale, conforme a la siguiente distribución: 


\begin{tabular}{|l|l|}
\hline Asignaturas & $\mathrm{f}$ \\
\hline Ciencias Biológicas & 12 \\
Física & 4 \\
Química & 4 \\
\hline & 20 \\
\hline
\end{tabular}

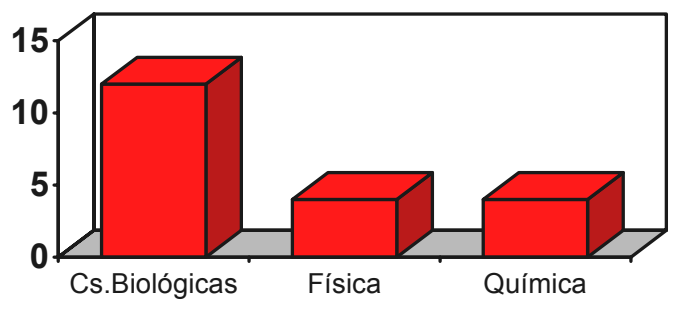

Siete docentes habían asistido a cursos de Historia y Filosofía de la Ciencia, y trece no habían asistido.

\begin{tabular}{|lll|l|}
\hline $\begin{array}{l}\text { Asistencia a cursos de } \\
\text { Historia y Filosofía de la } \\
\text { ciencia }\end{array}$ & \\
\hline $\begin{array}{l}\text { Asistieron } \\
\text { No Asistieron }\end{array}$ & 7 \\
\hline & 13 \\
\hline
\end{tabular}

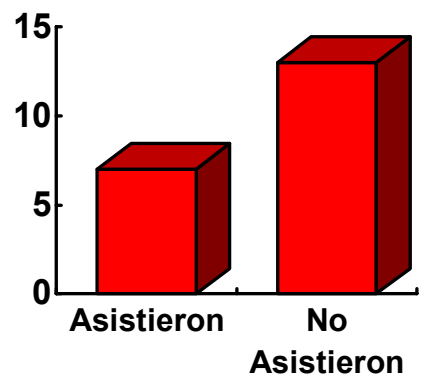

La antigüedad laboral promedio es de ocho años aproximadamente.

\section{Instrumento de recolección de datos}

La información se obtuvo a través de un cuestionario (ver anexo) compuesto por quince ítemes a los que el encuestado debía responder seleccionando una o más alternativas según el caso. Del conjunto total de ítemes, seis exploraban las concepciones de los docentes acerca de la ciencia, y los restantes indagaban aspectos vinculados a la práctica del docente en la enseñanza de la ciencia.

La versión original del instrumento fue sometida a aplicación piloto a los efectos de determinar si las instrucciones y los ítemes resultaban suficientemente claros, de donde surgió la necesidad de revisar y reelaborar algunos de ellos.

\section{Presentación, análisis e interpretación de los datos}

La estructura de este apartado se realiza en función de cada uno de los ítemes que componen el cuestionario.

\section{Concepción de ciencia}

\begin{tabular}{|c|c|c|c|c|c|}
\hline \multirow{3}{*}{$\begin{array}{l}\text { ¿Cuál de las siguientes definiciones } \\
\text { considera } \\
\text { Ud. que refleja más adecuadamente su } \\
\text { concepción de ciencia? }\end{array}$} & \multirow[t]{2}{*}{ Total } & \multicolumn{4}{|c|}{ Asistencia a CHFC } \\
\hline & & $\mathrm{S}$ & & $\mathrm{N}$ & \\
\hline & $f \%$ & $f$ & $f \%$ & $f$ & $\mathrm{f} \%$ \\
\hline a. Es un producto compuesto por hechos, & & & & & \\
\hline
\end{tabular}


teorías, etc. que constituyen un cuerpo organizado de conocimientos.

b. Es el producto de un proceso de construcción de la realidad, sometido a influencias políticas, sociales, culturales e históricas.

Nota: Nota: CHFC: Cursos de Historia y Filosofía de la Ciencia.

f: Número de casos.

f\%: Porcentaje de casos.

\section{$\underline{\text { Total de docentes }}$}

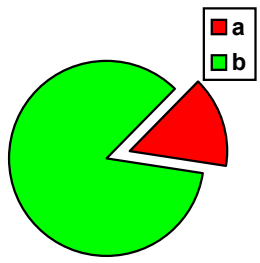

Docentes que asistieron a cursos

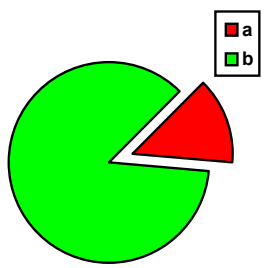

Docentes que no asistieron a cursos

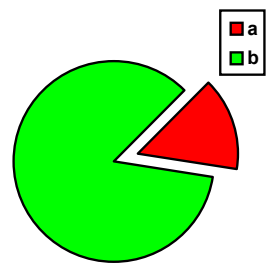

Sólo el $15 \%$ de los docentes adhiere a la concepción clásica de la ciencia. Desde esta perspectiva, se tiene una imagen estática, concibiéndose la ciencia como un producto, lo cual tiene poca relación con la práctica real y concreta de los científicos. Desde esta concepción positivista, el conocimiento es considerado como una entidad que el alumno debe incorporar. Para lograrlo es necesario que lo fraccione, y así se produce la atomización del saber y se deja de lado la noción de totalidad.

La mayoría de los docentes (85\%) sustenta una concepción de ciencia que intenta descubrir los procesos de producción presentes en la construcción del conocimiento. Esta postura, superadora del enfoque positivista, rescata la importancia del conocimiento de los hechos, de las relaciones entre ellos y de los procesos a través de los cuales se producen dichos hechos y se intenta conocerlos. Partir de esta concepción implica que el docente debe presentar el conocimiento destacando su evolución, las dificultades y los problemas que generaron su construcción.

Para establecer si la asistencia o no a cursos de Historia y Filosofía de la Ciencia influye en la concepción de ciencia que se sustenta, se aplicó el coeficiente de asociación $Q$ de Yule.

Asistencia a cursos de HFC

Respuestas

al ítem 1 a

b

\begin{tabular}{|c|c|c|}
\hline $\mathrm{Si}$ & No & \\
\hline $\begin{array}{l}1 \\
(\mathrm{~A})\end{array}$ & $\begin{array}{l}2 \\
\text { (B) }\end{array}$ & 3 \\
\hline $\begin{array}{l}6 \\
(\mathrm{C}) \\
\end{array}$ & $\begin{array}{l}11 \\
\text { (D) } \\
\end{array}$ & 17 \\
\hline 7 & 13 & 20 \\
\hline
\end{tabular}




$$
Q=\frac{(A)(D)-(B)(C)}{(A)(D)+(B)(C)}=\frac{(1)(11)-(2)(6)}{(1)(11)+(2)(6)}=-\frac{1}{23}=-0,04
$$

El valor obtenido muestra que el hecho de haber asistido o no a cursos de HFC no incide en el modo de concebir la ciencia que poseen los docentes.

\section{Características de las teorías científicas}

\begin{tabular}{|c|c|c|c|c|c|c|}
\hline \multirow{3}{*}{$\begin{array}{l}\text { Las teorías científicas están constituidas } \\
\text { por: }\end{array}$} & \multirow{2}{*}{\multicolumn{2}{|c|}{ Total }} & \multicolumn{4}{|c|}{ Asistencia a CHFC } \\
\hline & & & \multicolumn{2}{|c|}{$\mathrm{Si}$} & \multicolumn{2}{|c|}{ No } \\
\hline & $f$ & $f \%$ & $f$ & $f \%$ & $f$ & $f \%$ \\
\hline $\begin{array}{l}\text { a. Conocimientos que tienen carácter } \\
\text { provisional y tentativo }\end{array}$ & 10 & 50 & 1 & 14 & 9 & 69 \\
\hline $\begin{array}{l}\text { b. Conocimientos que expresan } \\
\text { verdades absolutas y universales }\end{array}$ & 10 & 50 & 6 & 86 & 4 & 31 \\
\hline & 20 & 100 & 7 & 100 & 13 & 100 \\
\hline
\end{tabular}

Total de docentes Docentes que asistieron a Docentes que no asistieron cursos
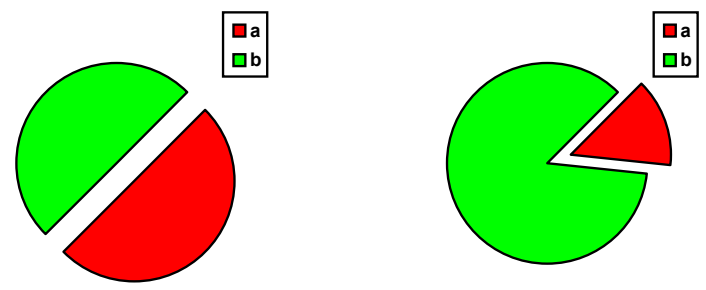

a cursos

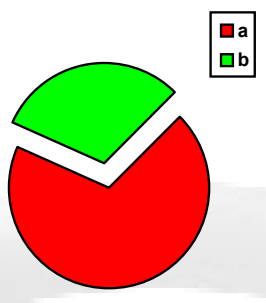

El contenido de este ítem está estrechamente vinculado al anterior, dado que se esperaba que la mayoría de los docentes hubiesen optado por la alternativa a. Sin embargo, las elecciones se distribuyeron entre ambas opciones con igual porcentaje.

Resulta sorprendente, por otra parte, la relación encontrada entre las respuestas dadas y la asistencia o no a cursos de Historia y Filosofía de la ciencia. Para determinar dicha asociación, se aplicó el coeficiente $\mathrm{Q}$.

Asistencia a Cursos de HFC

$\begin{array}{ll}\text { Respuestas } & a \\ \text { al ítem } 2 & b\end{array}$

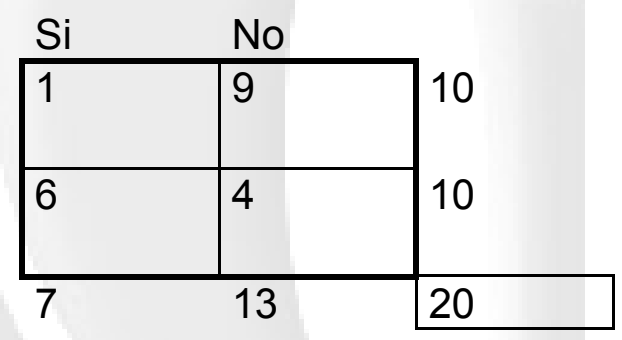




$$
Q=\frac{(1)(4)-(9)(6)}{(1)(4)+(9)(6)}=-\frac{50}{58}=-0,86
$$

El valor del coeficiente indica que la intensidad de la asociación es alta y su dirección negativa, lo que significa que la mayoría de los docentes que contestan que las teorías científicas están constituidas por conocimientos provisionales y tentativos, no asistieron a dichos cursos, en tanto que la mayoría de los que consideran que los conocimientos expresan verdades absolutas y universales, habían asistido a cursos. Estos resultados son contradictorios a los esperados, ya que la asistencia a cursos específicos de formación no han dotado a los profesores de las herramientas conceptuales que necesitan para concebir el conocimiento como algo provisional, que puede ser modificado.

\section{Teoría y observación}

\begin{tabular}{|l|l|l|l|l|l|l|l|}
\hline & \multicolumn{3}{|l|}{ Total } & \multicolumn{3}{|l|}{ Asistencia a CHFC } \\
\cline { 4 - 9 } $\begin{array}{l}\text { Las observaciones que realiza el } \\
\text { científico en } \\
\text { su actividad de búsqueda y y } \\
\text { descubrimiento: }\end{array}$ & & $\mathrm{f}$ & $\mathrm{f} \%$ & $\mathrm{f}$ & $\mathrm{f} \%$ & $\mathrm{f}$ & $\mathrm{f} \%$ \\
\hline $\begin{array}{l}\text { a. Están condicionadas por sus marcos teóricos } \\
\text { y conceptuales. }\end{array}$ & 16 & 80 & 6 & 86 & 10 & 77 \\
b. Están libres de teoría, son neutrales & 4 & 20 & 1 & 14 & 3 & 23 \\
\hline & 20 & 100 & 7 & 100 & 13 & 100 \\
\hline
\end{tabular}

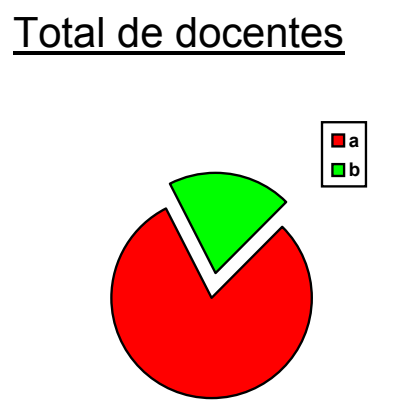

\section{Docentes que asistieron a cursos}

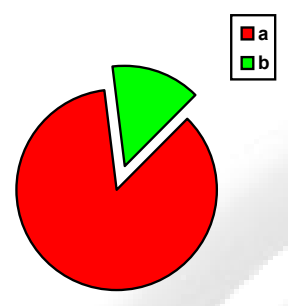

Docentes que no asistieron a cursos

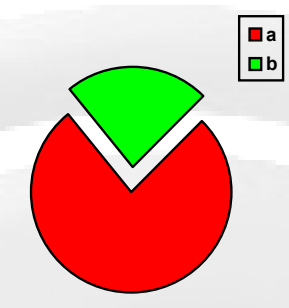

El $80 \%$ de los docentes considera que las teorías y los marcos conceptuales condicionan la observación del científico y su modo de interpretar la realidad. De este modo, investigadores adherentes a distintas teorías pueden observar fenómenos distintos, aun cuando se trate de los mismos hechos. Sólo el $20 \%$ de los profesores de ciencias concibe al investigador como un observador neutral, objetivo. La aplicación del coeficiente $Q$ permitió determinar la relación existente entre las respuestas dadas al ítem y la asistencia o no a cursos de HFC. 
Asistencia a cursos de HFC

\begin{tabular}{ll|l|l|l|} 
Respuestas & a & 6 & 10 \\
al ítem 3 & $\mathrm{~b}$ & 1 & 3 & 4 \\
\hline 7 & 13 & 20 \\
\hline & $\mathrm{Q}=\frac{(6)(3)-(10)(1)}{(6)(3)+(10)(1)}=\frac{8}{28}=0,28$
\end{tabular}

El valor obtenido indica bajo grado de asociación entre ambos factores. Quienes optaron por la alternativa a, en su mayoría no habían asistido a cursos de HFC, y quienes optaron por la alternativa $b$, en su mayoría tampoco habían asistido.

\section{Objetividad del conocimiento científico}

\begin{tabular}{|c|c|c|c|c|c|c|}
\hline \multirow{3}{*}{ El conocimiento científico se caracteriza por ser: } & \multirow{2}{*}{\multicolumn{2}{|c|}{ Total }} & \multicolumn{4}{|c|}{ Asistencia a CHFC } \\
\hline & & & \multicolumn{2}{|c|}{$\mathrm{Si}$} & \multicolumn{2}{|c|}{ No } \\
\hline & $f$ & $f \%$ & $f$ & $f \%$ & $f$ & $f \%$ \\
\hline \multicolumn{7}{|l|}{$\begin{array}{l}\text { a. Una copia fiel de la realidad, el conocimiento } \\
\text { obtenido se corresponde fielmente con la cosa } \\
\text { conocida. }\end{array}$} \\
\hline \multirow{3}{*}{$\begin{array}{l}\text { b. Una representación de la realidad, en cuya } \\
\text { construcción intervienen factores que afectan la } \\
\text { objetividad. }\end{array}$} & 6 & 30 & 1 & 14 & 5 & 38 \\
\hline & 14 & 70 & 6 & 86 & 8 & 62 \\
\hline & 20 & 100 & 7 & 100 & 13 & 100 \\
\hline
\end{tabular}

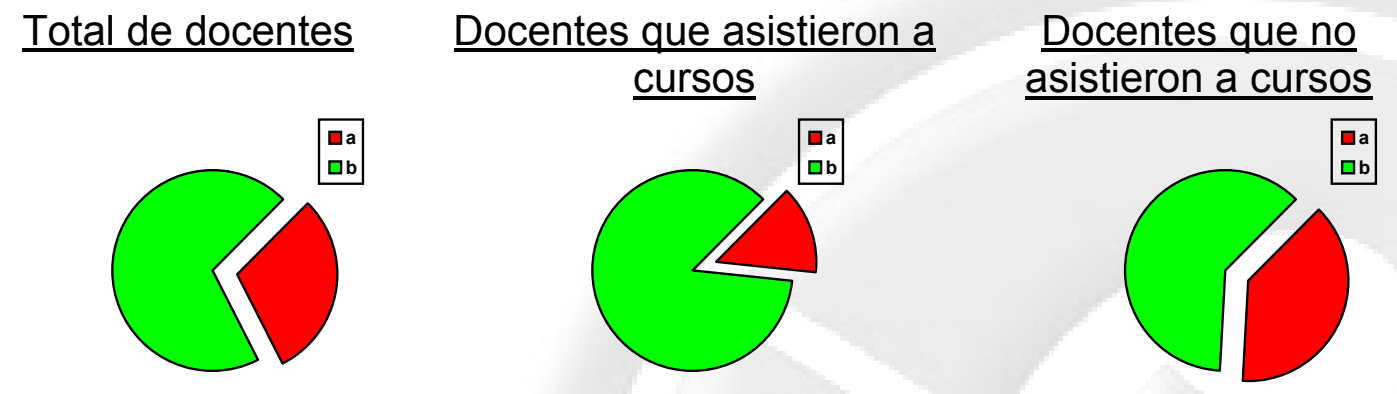

El $70 \%$ de los docentes de ciencias considera que en la actividad cognoscitiva científica interviene un conjunto de factores que afectan o distorsionan la objetividad del conocimiento. Para que el conocimiento fuese en realidad objetivo, el investigador debería despojarse de su carga de valores, deseos, intereses, etc., lo cual resulta imposible por ser inherentes a su condición de ser humano. De allí el carácter falible del conocimiento, su posibilidad de caer en el error. Sólo el 30\% de los profesores entiende que la objetividad es una característica del conocimiento científico. Para determinar cómo incide el hecho de haber asistido o no a cursos de HFC en las respuestas proporcionadas por los docentes, se obtuvo el valor del coeficiente de asociación $Q$ 
Asistencia a cursos de HFC

Respuestas

al ítem 4 a

b

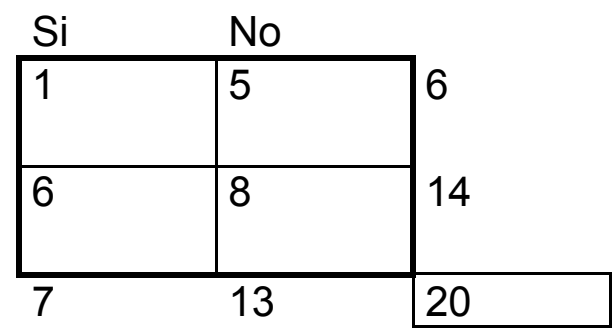

$$
Q=\frac{(1)(8)-(5)(6)}{(1)(8)+(5)(6)}=-\frac{22}{38}=-0,57
$$

La dirección de la asociación es negativa, pero de intensidad moderada, dado que:

a) La mayoría de los docentes que optan por la alternativa a, no han asistido a cursos de Historia y Filosofía de la Ciencia.

b) La mayoría de los que optan por la alternativa $b$, tampoco han asistido a dichos cursos.

\section{Visión que se posee de la actividad científica}

\begin{tabular}{|c|c|c|c|c|c|c|}
\hline \multirow{3}{*}{$\begin{array}{l}\text { El conocimiento científico es el fruto de una } \\
\text { ardua tarea llevada a cabo por: }\end{array}$} & \multirow{2}{*}{\multicolumn{2}{|c|}{ Total }} & \multicolumn{4}{|c|}{ Asistencia a CHFC } \\
\hline & & & \multicolumn{2}{|c|}{$\mathrm{Si}$} & \multicolumn{2}{|l|}{ No } \\
\hline & $f$ & f\% & $f$ & $f \%$ & $f$ & $\mathrm{f} \%$ \\
\hline $\begin{array}{l}\text { Personas (genios) que trabajan aisladamente en } \\
\text { sus laboratorios (torres de marfil) con el } \\
\text { objetivo de poner a prueba sus hipótesis. }\end{array}$ & 5 & 25 & 1 & 14 & 4 & 31 \\
\hline \multirow[t]{2}{*}{$\begin{array}{l}\text { b. Una comunidad que trabaja en un contexto } \\
\text { histórico y social con el propósito de generar } \\
\text { nuevos conocimientos. }\end{array}$} & 15 & 75 & 6 & 86 & 9 & 69 \\
\hline & 20 & 100 & 7 & 100 & 13 & 100 \\
\hline
\end{tabular}

Total de docentes Docentes que asistieron a Docentes que no asistieron cursos
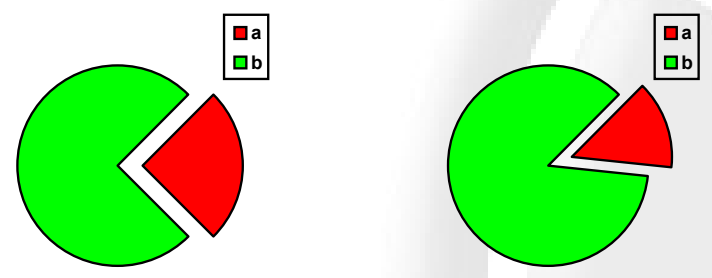

\section{a cursos}

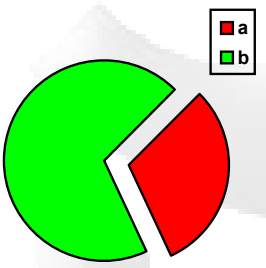

Un bajo porcentaje de docentes (25\%) posee una visión individualista y descontextualizada de la ciencia. Considera los conocimientos científicos como obra de 
genios aislados, encerrados en torres de marfil, e ignora el papel del trabajo colectivo y de los intercambios que se producen entre los equipos.

La mayoría de los profesores (75\%) percibe la investigación como una actividad llevada a cabo por grupos de individuos (científicos). Desde esta perspectiva, sus actos están regidos en buena medida por las expectativas que la comunidad investigadora mantiene con respecto a sus miembros, y que provienen del paradigma imperante. El valor que arrojó el coeficiente de asociación $Q$ permite determinar cómo incide en las respuestas proporcionadas por los docentes el hecho de haber asistido o no a cursos de HFC.

Asistencia a cursos de HFC

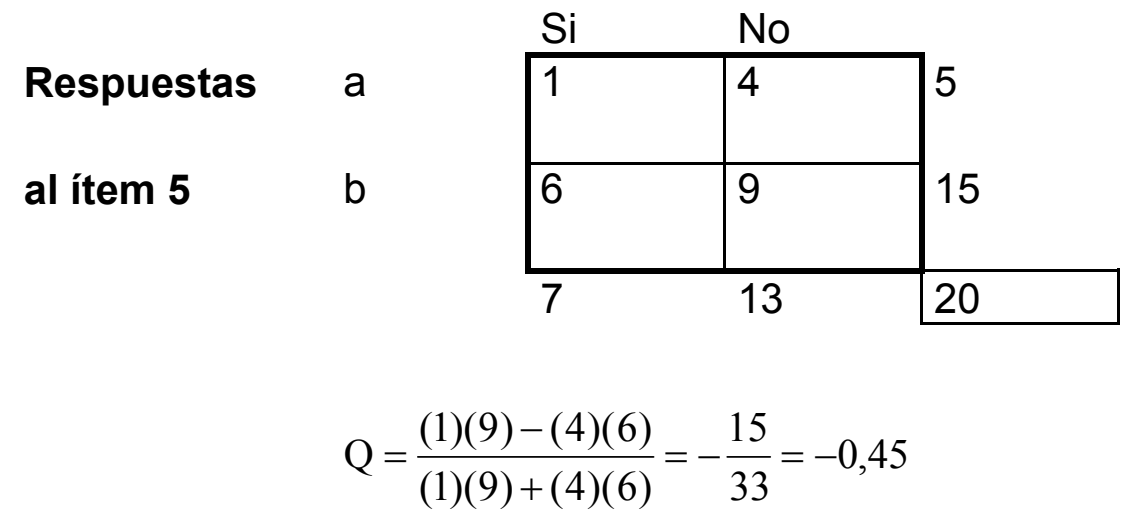

La intensidad de la asociación es moderada y su dirección negativa: a) Los docentes que expresan que el conocimiento es fruto de personas aisladas, en su mayoría no asistió a cursos de HFC, y b) Los docentes que estiman que el conocimiento es fruto de una actividad que tiene lugar en comunidades sociales, se distribuyen en ambas celdas, siendo más elevado el número de quienes no asistieron a dichos cursos.

\section{El progreso de la ciencia}

\begin{tabular}{|c|c|c|c|c|c|c|}
\hline \multirow[t]{3}{*}{ La ciencia puede ser considerada como: } & \multirow{2}{*}{\multicolumn{2}{|c|}{ Total }} & \multicolumn{4}{|c|}{ Asistencia a CHFC } \\
\hline & & & \multicolumn{2}{|c|}{$\mathrm{Si}$} & \multicolumn{2}{|c|}{ No } \\
\hline & $f$ & $f \%$ & $f$ & $f \%$ & $f$ & $f \%$ \\
\hline $\begin{array}{cccc}\text { Un proceso no lineal que presenta } & \text { no } \\
\text { discontinuidades } & \text { caracterizadas por el } \\
\text { surgimiento de nuevos marcos conceptuales. }\end{array}$ & 14 & 70 & 5 & 71 & 9 & 69 \\
\hline $\begin{array}{l}\text { b. Un proceso acumulativo y lineal de } \\
\text { conocimientos y verdades definitivas sobre la } \\
\text { naturaleza. }\end{array}$ & 6 & 30 & 2 & 29 & 4 & 31 \\
\hline & 20 & 100 & 7 & 100 & 13 & 100 \\
\hline
\end{tabular}



cursos

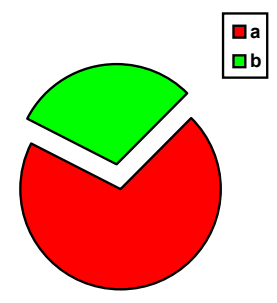

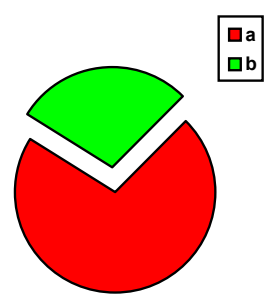

a cursos

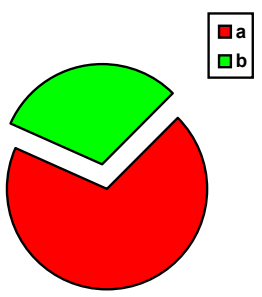

El 30\% de los docentes de ciencia, en una postura acorde con la tradición positivista, admite que el saber científico se halla en un proceso de continua acumulación, que contribuye a incrementar el capital de conocimientos válidos y verdaderos. Sin embargo, el porcentaje más elevado (70\%) expresa que el desarrollo del saber científico se puede concebir como una sucesión de revoluciones en el curso de las cuales resultan derribados y remplazados los paradigmas predominantes. Como lo muestra el valor del coeficiente obtenido, la asociación entre las respuestas dadas al ítem y la asistencia o no a cursos de HFC es prácticamente nula.

Asistencia a cursos de HFC

$\begin{array}{ll}\text { Respuestas } & a \\ \text { al ítem } 6 & b\end{array}$

\begin{tabular}{|l|l|l|}
\multicolumn{1}{|c|}{$\mathrm{Si}$} & No & \multirow{2}{*}{14} \\
\hline 5 & 9 & 6 \\
\hline 2 & 4 & 6 \\
\hline 7 & 13 & 20 \\
\hline
\end{tabular}

$$
\mathrm{Q}=\frac{(5)(4)-(9)(2)}{(5)(4)+(9)(2)}=\frac{2}{38}=0,05
$$

\section{Planificación de las actividades de enseñanza}

\begin{tabular}{|l|c|c|}
\hline $\begin{array}{l}\text { Al diseñar una acción pedagógica eficaz, lo más } \\
\text { importante es: }\end{array}$ & $\mathrm{f}$ & $\mathrm{f} \%$ \\
\hline $\begin{array}{l}\text { a. Partir de metas generales que orienten la acción sin } \\
\text { preocuparse por predeterminar el resultado final. }\end{array}$ & & \\
\hline $\begin{array}{l}\text { b. Partir de objetivos claros y definidos que indiquen los } \\
\text { resultados que se desean obtener en términos de } \\
\text { conducta. }\end{array}$ & 4 & 21 \\
\hline & 15 & 79 \\
\hline
\end{tabular}

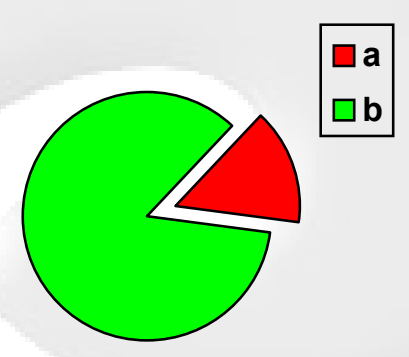

Nota: *Un docente no responde al ítem.

El mayor porcentaje de docentes (79\%) planifica las actividades, especificando los objetivos por alcanzar en términos de conductas observables, por lo que su actuación se reduce a la selección y aplicación de los medios adecuados para alcanzar dichos objetivos. Desde esta perspectiva, el énfasis está puesto más en el resultado de la enseñanza que en el proceso mismo, práctica que resulta coherente con una postura 
positivista. Sólo el $21 \%$ de los sujetos de la muestra expresa partir de metas generales que orientan su acción, lo que posibilita una intervención más flexible y acorde con las características del grupo específico de alumnos y con la situación particular de clase.

\section{Tipo de intervención docente}

\begin{tabular}{|l|c|c|}
\hline $\begin{array}{l}\text { Su intervención en el aula consiste } \\
\text { fundamentalmente en: }\end{array}$ & $\mathrm{f}$ & \\
\hline $\begin{array}{l}\text { a. Aplicar de modo uniforme ciertas } \\
\text { formas de actuar que se desprenden de } \\
\text { teorías elaboradas por los científicos.. }\end{array}$ & 3 & 15 \\
\hline $\begin{array}{l}\text { b. Actuar en forma autónoma, tomando } \\
\text { sus propias decisiones en cada } \\
\text { situación particular. }\end{array}$ & 17 & \\
\hline & 20 & \\
\hline
\end{tabular}

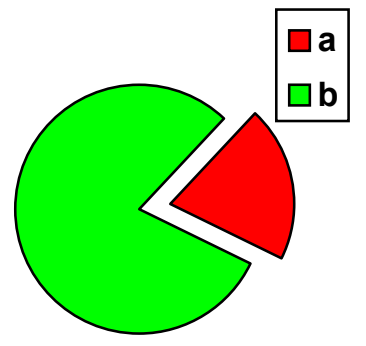

El $85 \%$ de los docentes expresa que su intervención en el aula no sigue recetas preestablecidas, sino que se realiza en función de las necesidades del grupo específico de alumnos y de la multiplicidad de variables que entran en juego en el proceso de enseñanza-aprendizaje. Sólo el 15\% realiza una intervención de tipo técnica, utilizando principios genéricos válidos para cualquier grupo de alumnos, sin atender a su especificidad. Este tipo de intervención resulta acorde con una postura positivista.

\section{Modo de transmitir los conocimientos científicos}

\begin{tabular}{|l|l|l|l|}
\hline $\begin{array}{l}\text { El objetivo fundamental de las clases de } \\
\text { ciencias es: }\end{array}$ & f\% \\
\hline $\begin{array}{l}\text { a. Transmitir el corpus de conocimientos } \\
\text { o verdades absolutas adquiridas por los } \\
\text { científicos. }\end{array}$ & 4 & 20 \\
\hline $\begin{array}{l}\text { b. Presentar los conocimientos como } \\
\text { conjeturables y problemáticos, } \\
\text { destacando su evolución y los } \\
\text { problemas que generaron su } \\
\text { construcción. }\end{array}$ & & \\
\hline
\end{tabular}

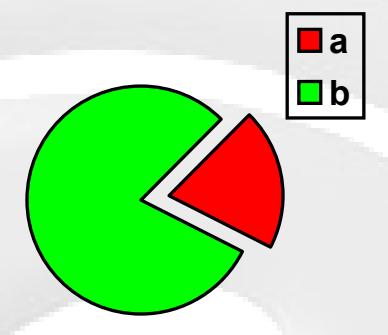

La mayoría de los docentes (80\%) presenta los conocimientos de ciencias como conjeturables y problemáticos, destacando el proceso seguido en su construcción. Es interesante, tratar de establecer si el modo en que los docentes transmiten los 
conocimientos a sus alumnos (ítem 9), es coherente con su concepción del conocimiento científico (ítem 2). Para ello, se aplicó el coeficiente $Q$ de Yule.

Respuestas al ítem 2

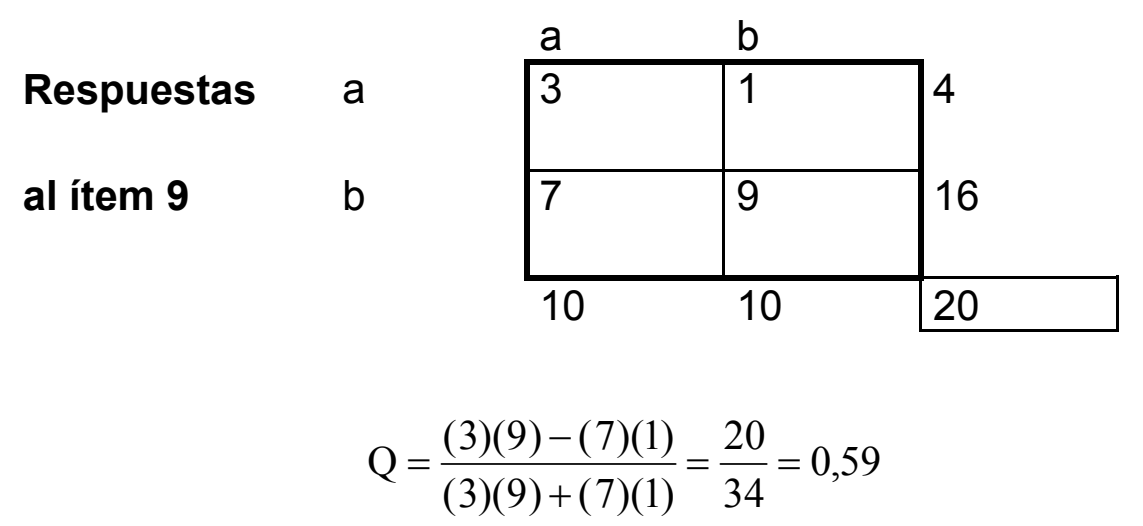

El grado de asociación es moderada y su dirección positiva, lo que indica que en general los que consideran que el conocimiento tiene carácter provisional, en sus clases de ciencias lo transmiten como verdades absolutas, y quienes consideran el conocimiento como verdades universales, las presentan a sus alumnos como conjeturables $y$ problemáticas.

\section{Forma en que se realiza el aprendizaje de los conceptos científicos}

\begin{tabular}{|l|l|l|}
\hline $\begin{array}{l}\text { El aprendizaje de la ciencia por parte de } \\
\text { los alumnos, se lleva a cabo: }\end{array}$ & $f \%$ \\
\hline $\begin{array}{l}\text { a. Asimilando conceptos correctos } \\
\text { desde el punto de vista de la disciplina. } \\
\text { b. Modificando sus propias teorías al } \\
\text { tomar conciencia de que éstas no les } \\
\text { sirven para explicar la realidad.. }\end{array}$ & 6 & 32 \\
\hline & 13 & 68 \\
\hline
\end{tabular}

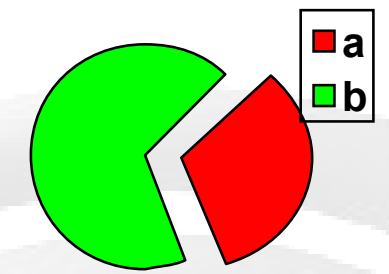

Nota: *Un docente no responde al ítem.

El $68 \%$ de los profesores plantea que en el aprendizaje de los conceptos científicos se debe establecer una conexión entre la teoría espontánea del alumno y la teoría que se va a transmitir. Enseñar ciencia, para estos docentes, consiste en cambiar los conceptos espontáneos de los alumnos.

Un porcentaje bastante inferior (32\%), en cambio, considera que los alumnos aprenden ciencia asimilando conceptos correctos desde el punto de vista de la disciplina. El docente, por tanto, debería proporcionar dichos conceptos. 


\section{Estrategias utilizadas en la enseñanza de las ciencias}

\begin{tabular}{|c|c|c|c|c|c|c|c|c|c|c|c|c|c|c|c|}
\hline \multirow{2}{*}{$\begin{array}{l}\text { La estrategia a la que asigna prioridad } \\
\text { en el proceso de enseñanza } \\
\text { aprendizaje es: } \\
\text { (Asigne un orden de importancia } \\
\text { colocando el número correspondiente } \\
\text { delante de cada alternativa) }\end{array}$} & \multicolumn{2}{|c|}{$\begin{array}{l}\text { 1er. } \\
\text { lugar }\end{array}$} & \multicolumn{2}{|c|}{$\begin{array}{l}\text { 2do. } \\
\text { lugar }\end{array}$} & \multicolumn{2}{|c|}{$\begin{array}{l}\text { 3er. } \\
\text { lugar }\end{array}$} & \multicolumn{2}{|c|}{$\begin{array}{l}\text { 4to. } \\
\text { lugar }\end{array}$} & \multicolumn{2}{|c|}{$\begin{array}{l}\text { 5to. } \\
\text { lugar }\end{array}$} & \multicolumn{2}{|c|}{$\begin{array}{l}\text { 6to. } \\
\text { lugar }\end{array}$} & \multicolumn{2}{|c|}{$\begin{array}{l}7 \mathrm{mo} . \\
\text { lugar }\end{array}$} & \multirow[t]{2}{*}{$\begin{array}{l}\text { To- } \\
\text { tal }\end{array}$} \\
\hline & $f$ & $\mathrm{f} \%$ & $f$ & $f \%$ & $f$ & $f \%$ & $f$ & $\mathrm{f} \%$ & $f$ & $\mathrm{f} \%$ & $f$ & $f \%$ & $f$ & $\mathrm{f} \%$ & \\
\hline a. Contacto con la realidad. & 9 & 47 & 4 & 21 & 4 & 21 & & & 2 & 11 & & & & & 19 \\
\hline b. La exposición magistral del profesor. & 1 & 5 & 3 & 16 & 1 & 5 & 1 & 5 & & & 4 & 21 & 9 & 47 & 19 \\
\hline $\begin{array}{l}\text { c. La investigación sobre el problema } \\
\text { siguiendo los pasos del método } \\
\text { científico. }\end{array}$ & 3 & 16 & 5 & 26 & 4 & 21 & 3 & 16 & 1 & 5 & 1 & 5 & 2 & 11 & 19 \\
\hline d. La discusión en pequeños grupos. & 5 & 26 & 4 & 21 & 4 & 21 & 2 & 11 & 2 & 11 & 1 & 5 & 1 & 5 & $\overline{19}$ \\
\hline e. La utilización de libros de texto. & & & 1 & 5 & 3 & 16 & 6 & 31 & 6 & 31 & 3 & 16 & & & 19 \\
\hline f. Las experiencias de laboratorio. & 1 & 5 & 1 & 5 & 2 & 11 & 6 & 31 & 5 & 26 & 3 & 16 & 1 & 5 & 19 \\
\hline $\begin{array}{l}\text { g. La preparación y exposición de un } \\
\text { tema por parte de los alumnos. }\end{array}$ & & & 1 & 5 & 1 & 5 & 1 & 5 & 3 & 16 & 7 & 37 & 6 & 31 & 19 \\
\hline h. Otros (especifique). & & & & & & & & & & & & & & & \\
\hline
\end{tabular}

Las estrategias didácticas por desarrollar en el aula, deben seleccionarse en función del tipo de aprendizaje que se desea obtener.

La información recogida muestra que las estrategias a las que la mayoría de los docentes otorga el primer lugar son: el contacto con la realidad y la discusión en pequeños grupos, y el segundo lugar, a la investigación sobre un problema. Se pone énfasis en aquellas actividades de trabajo colectivo, desarrolladas por equipos o grupos de alumnos.

La investigación en el aula, si se la utiliza adecuadamente, constituye una de las vías posibles para que el alumno logre un aprendizaje significativo y es una propuesta coherente con la idea de construcción del conocimiento. El estudiante sólo podrá comprender y explicar aquello en lo que ha tenido una participación activa.

El aprendizaje a través de la investigación, al promover la participación activa en las distintas fases o momentos del proceso y enfrentar al alumno a múltiples situaciones en las que deberá poner en juego distintas habilidades, contribuye a favorecer su desarrollo y progreso intelectual.

Por otra parte, esta actividad, realizada en forma grupal, fomenta el respeto mutuo entre los alumnos y el respeto a las ideas de los demás y permite descubrir sus propias capacidades y limitaciones. En las discusiones de grupo, en el diálogo, el alumno aprende a confrontar distintos puntos de vista, a ponerse en lugar del otro, lo que también le resulta beneficioso.

La utilización de los libros de texto se ubicada en el cuarto y quinto lugar, encontrándose también en una posición intermedia (4o. lugar) las experiencias de laboratorio.

Los libros y manuales, en general, presentan la ciencia descontextualizada; el conocimiento científico pierde así su carácter de proceso y se lo visualiza como un producto objetivo, acabado, que representa una verdad universal. 
Las estrategias didácticas ubicadas en los últimos lugares (6o. y 7o.) en función de la importancia que los docentes les asignan son: la preparación y exposición de un tema por parte de los alumnos y la exposición magistral del profesor, respectivamente. Estas estrategias, de carácter más tradicional en la enseñanza de las ciencias, llevan con frecuencia al enciclopedismo y a la memorización en el aprendizaje.

\section{Modo de realizar la evaluación}

\begin{tabular}{|l|l|l|}
\hline $\begin{array}{l}\text { En el momento de evaluar, el interés se } \\
\text { centra fundamentalmente: }\end{array}$ & $\mathrm{f} \%$ \\
\hline $\begin{array}{l}\text { a. En conocer el camino que recorrió el } \\
\text { alumno para llegar a la respuesta. }\end{array}$ & 13 & 65 \\
$\begin{array}{l}\text { b. En conocer el resultado o corrección } \\
\text { de la respuesta dada por el alumno, } \\
\text { para otorgar una calificación. }\end{array}$ & 7 & 35 \\
\hline & 20 & 100 \\
\hline
\end{tabular}

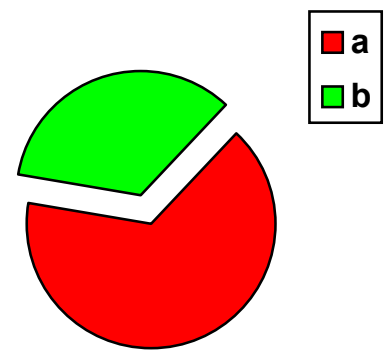

Los profesores que consideran la evaluación como el proceso de comprensión del camino realizado por el alumno, representan el porcentaje más alto (65\%). Desde esta perspectiva, es importante conocer los logros, los obstáculos, los errores, las carencias, etc., que se presentan en ese proceso. Un 35\% de los docentes de la muestra entiende que la evaluación mide sólo productos, dejando de lado los aspectos más valiosos. Confunden evaluación con acreditación y clasificación. Si partimos del supuesto de que la concepción de ciencia sustenta la práctica del docente, es de esperar que si se concibe la ciencia como cerrada, acabada e incuestionable, se evalúen sólo productos, en tanto que si se considera la ciencia como una producción histórica, en permanente construcción, inacabada, cuestionable, abierta, se evalúen también las dificultades y los logros del alumno en el proceso de aprendizaje.

Para establecer la relación entre el modo de concebir el conocimiento científico (ítem 2) y la forma de evaluar de los docentes (ítem 12), se aplicó el coeficiente Q.

Respuestas al ítem 2

(modo de concebir el conocimiento científico)

Respuestas

al ítem 12

(forma de evaluación)

$a \quad b$

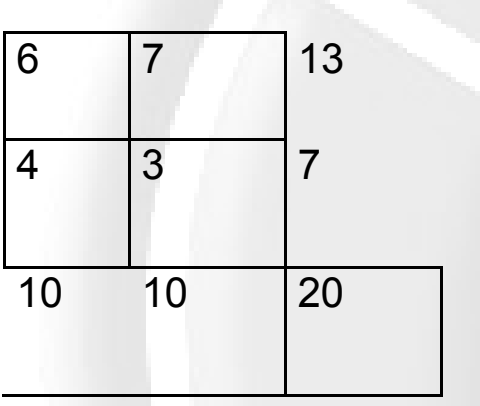

$$
Q=\frac{(6)(3)-(7)(4)}{(6)(3)+(7)(4)}=-\frac{10}{46}=-0,22
$$

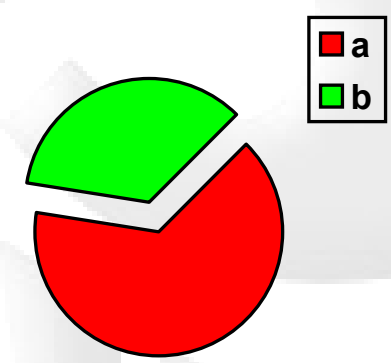


Si bien el valor que arroja el coeficiente expresa baja asociación, su dirección indica que existiría cierta tendencia a que quienes conciben el conocimiento como verdades absolutas y universales, en el momento de evaluar traten de conocer el camino que recorrió el alumno para llegar a la respuesta, y a que aquellos docentes que consideran el conocimiento como provisional y tentativo, evalúen en función del resultado final al que llegó el estudiante.

\section{Indagación de las ideas previas de los alumnos}

\begin{tabular}{|l|l|l|}
\hline $\begin{array}{l}\text { Realiza Ud. algún tipo de evaluación } \\
\text { para explorar los conocimientos de los } \\
\text { alumnos antes de iniciar un tema }\end{array}$ & f $\%$ \\
\hline $\begin{array}{l}\text { a. Si. } \\
\text { b. No. }\end{array}$ & 16 & 84 \\
\hline & $19^{*}$ & 100 \\
\hline
\end{tabular}

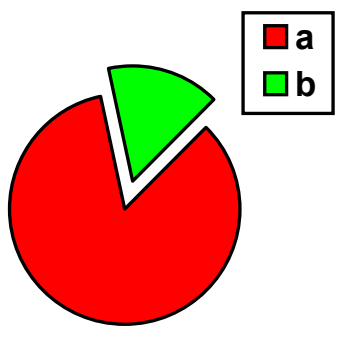

Nota: *Un docente no responde al ítem.

Sólo el 16\% de los docentes, al no realizar evaluación inicial, enseña ciencia al margen de las ideas que tienen los alumnos. De este modo, se produce una separación entre lo que se recibe en la escuela y el conocimiento espontáneo que tiene el alumno, dificultando el logro de un aprendizaje significativo.

Desde una concepción constructivista, se atribuye, sin embargo, especial importancia a las representaciones o conocimientos previos del alumno. El $84 \%$ de los docentes realiza una evaluación inicial para conocer los conocimientos que poseen los estudiantes respecto del contenido específico que se va a aprender. Conociendo estas representaciones iniciales, el profesor debe realizar intentos para que el alumno, a partir de la toma de conciencia de que esas ideas previas entran en contradicción con los conocimientos científicos, logre un avance hacia el cambio conceptual.

Puesto que para modificar las teorías del alumno es necesario conocer sus ideas previas, las respuestas dadas a este ítem deberían estar relacionadas con las respuestas dadas al ítem 10. Para establecer esta asociación, se aplicó el coeficiente Q.

Respuestas al ítem 10

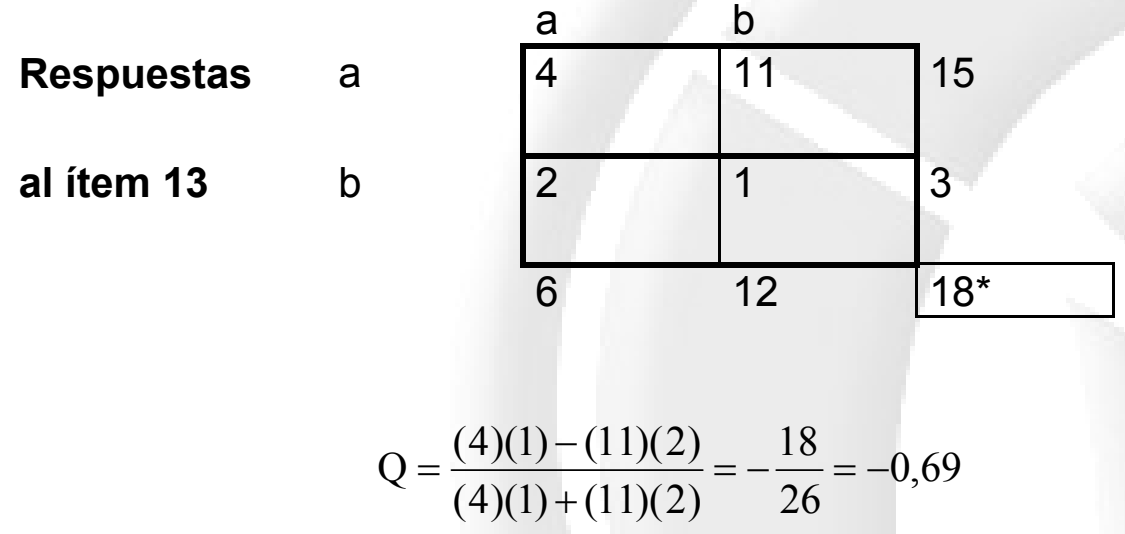

Nota: *Dos docentes respondieron a un solo ítem; por tal razón no se pudo realizar la tabulación correspondiente. 
La asociación tiende a ser alta y su dirección negativa, lo que indicaría que en general los docentes que consideran que el aprendizaje de la ciencia se lleva a cabo modificando las teorías que posee el alumno, realizan evaluaciones antes de iniciar un tema, en tanto que quienes consideran que aprender ciencia es asimilar conceptos correctos, no realizan evaluaciones iniciales.

\section{Objetivo de la evaluación inicial}

\begin{tabular}{|c|c|c|}
\hline $\begin{array}{l}\text { Si su respuesta al ítem anterior es afirmativa, } \\
\text { su principal objetivo es: }\end{array}$ & $\mathrm{f}$ & $f \%$ \\
\hline $\begin{array}{l}\text { a. Conocer si las concepciones que posee el } \\
\text { alumno son erróneas para ayudarle a modificarlas. }\end{array}$ & 1 & 6 \\
\hline $\begin{array}{l}\text { b. Motivar y despertar interés por la problemática } \\
\text { a. Conocer el nivel de conocimientos respecto al } \\
\text { tema, para no volver sobre lo enseñado. } \\
\text { b. Detectar problemas, dificultades y grado de } \\
\text { comprensión que poseen en relación al tema para } \\
\text { configurar un diagnóstico del grupo de clase. }\end{array}$ & $\begin{array}{l}5 \\
2 \\
8\end{array}$ & $\begin{array}{l}32 \\
12 \\
50\end{array}$ \\
\hline & $16^{*}$ & 100 \\
\hline
\end{tabular}

d

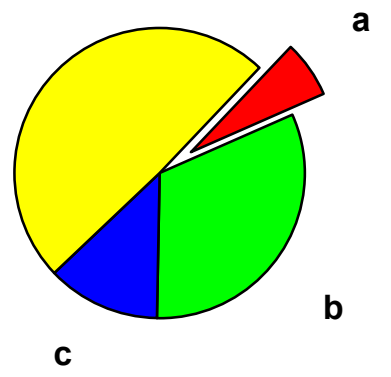

Nota: *Un docente no responde y tres no realizan evaluaciones iniciales

El $50 \%$ de los docentes realiza una evaluación inicial a fin de conocer las dificultades y el grado de comprensión de los alumnos respecto a un tema. Si bien esta evaluación les permite obtener un panorama acerca del nivel de conocimientos de sus alumnos, no la visualizan como requisito indispensable y punto de referencia a partir del cual se puedan plantear situaciones encaminadas a producir avances en el cambio conceptual. Destacan la situación grupal, descuidando la importancia que tiene, desde esta perspectiva, el perfil individual del alumno.

Un porcentaje inferior (32\%) considera que el conocimiento de los resultados de la evaluación inicial es una fuente de motivación para los alumnos. El tomar conciencia de sus dificultades puede producir deseos de superación. Sólo el 6\% (el porcentaje más bajo) evalúa con el propósito de conocer las concepciones del alumno para ayudarle a modificarlas en caso de que fuesen erróneas. 


\section{Instrumentos y técnicas de evaluación utilizados}

\begin{tabular}{|l|l|l|}
\hline $\begin{array}{l}\text { Si su respuesta al ítem 13 fue afirmativa. Para } \\
\text { evaluar los conocimientos que poseen los } \\
\text { alumnos al comenzar un tema, utiliza: }\end{array}$ & & \\
(Puede elegir más de una alternativa) & $\mathrm{f}$ & \\
\hline $\begin{array}{l}\text { a. Entrevistas individuales con los alumnos. } \\
\text { b. Cuestionarios. }\end{array}$ & 6 & 28 \\
$\begin{array}{l}\text { c. Pruebas objetivas. } \\
\text { d Pruebas con ítems que admiten varias } \\
\text { posibilidades de solución. }\end{array}$ & 4 & 19 \\
$\begin{array}{l}\text { e. Resolución de problemas sobre fenómenos } \\
\text { científicos }\end{array}$ & 2 & 10 \\
f. Otras (especifique) & 2 & 10 \\
\hline & 3 & 14 \\
\hline
\end{tabular}

d

C

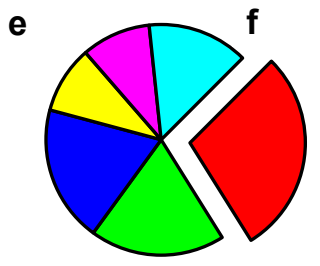

Nota: *Algunos docentes eligen más de una opción.

El ítem plantea la posibilidad de elegir más de una alternativa, puesto que las ideas de los alumnos, al ser construcciones personales, muchas veces carecen de coherencia y estabilidad, por lo que su evaluación suele presentar dificultades, más aún cuando se la realiza a través de un solo instrumento.

La técnica más utilizada por los docentes para evaluar los conocimientos previos es la entrevista individual con los alumnos, técnica que por su flexibilidad posibilita obtener información de gran riqueza. Otro instrumento empleado es el cuestionario, que resulta de gran utilidad dado que, al quedar registradas las respuestas por escrito, permite a los alumnos reflexionar sobre ellas en el transcurso del proceso de aprendizaje. También se utilizan las pruebas objetivas, en cuyo caso se transforma la evaluación en medición. Se corren el riesgo de medir únicamente memoria mecánica y de que pueda intervenir el azar. Este tipo de pruebas no permite la exploración de procesos más complejos, y ppor ello sería más adecuado, atendiendo a una concepción constructivista, el uso de instrumentos de tipo abierto y de mayor flexibilidad.

\section{Conclusiones}

Los docentes sustentan, en general, una concepción de ciencia superadora del enfoque positivista y que intenta aproximarse a lo que es, en realidad, la práctica concreta de los científicos.

Las notas que configuran sus creencias en relación con la ciencia son:

a) La ciencia es el producto de un proceso de construcción de la realidad, condicionado por influencias históricas, políticas, sociales y culturales.

b) Las observaciones que realiza el científico están en función de la teoría en virtud de la cual se llevan a cabo, no son neutrales.

c) El conocimiento obtenido no se corresponde fielmente con la cosa conocida; es una representación de la realidad, en cuya construcción intervienen factores que afectan la objetividad.

d) La investigación es una actividad llevada a cabo por la comunidad científica, dentro de un contexto histórico y social. Rechazan la visión individualista y descontextualizada de la concepción clásica de la ciencia. 
e) El desarrollo del quehacer científico se concibe como una sucesión de revoluciones en el curso de las cuales resultan derribados y remplazados los paradigmas dominantes y no como un proceso acumulativo y lineal de conocimientos y verdades definitivas sobre la naturaleza.

El carácter procesal y dinámico que los docentes atribuyen a la actividad científica implica, obviamente, que ningún conocimiento puede concebirse como definitivo, absoluto y válido para todo tiempo. Sin embargo, en este aspecto se evidencian contradicciones en las respuestas: docentes que consideran la ciencia como un proceso de construcción de la realidad, expresan que las teorías científicas están constituidas por conocimientos verdaderos, absolutos, universales.

Respecto a esta característica del conocimiento, el $50 \%$ de los profesores de ciencias le atribuye el carácter de provisional y tentativo, y el $50 \%$ restante considera que es verdadero, absoluto, universal, siendo el aspecto que menos discrimina entre las posturas que sustentan los docentes.

A partir del supuesto de que la asistencia a cursos de Historia y Filosofía de la Ciencia puede contribuir a que los docentes adquieran una mayor comprensión del quehacer científico, se estableció la asociación existente entre las respuestas dadas a cada uno de los ítemes y el haber asistido o no a dichos cursos. En este sentido, los resultados obtenidos muestran que en dos ítemes (1 y 6), la intensidad de la asociación es prácticamente nula, en uno (ítem 3) es baja y en otros dos ítemes (4 y 5) es moderada.

Sorprende el único caso (ítem 2) en que se obtiene un grado de asociación alto, con dirección negativa. Estos resultados son, sin duda, contradictorios a los esperados, puesto que quienes han asistido a cursos de HFC estiman que los conocimientos expresan verdades absolutas y universales, en tanto que quienes no han asistido los consideran provisionales, tentativos. La asistencia a dichos cursos, en este sentido, no ha contribuido a una mejor comprensión de la actividad científica.

En relación con la práctica en el aula, un alto porcentaje de docentes, al diseñar las actividades, propone un camino a seguir que les permita obtener determinados resultados en términos de conductas observables. El énfasis de su intervención está puesto en el producto de la enseñanza, práctica que resulta coherente con una postura positivista.

Sin embargo, manifiestan actuar en forma autónoma, tomando sus propias decisiones en cada situación particular, en cuyo caso su intervención se realizaría en función de las características de los alumnos y la multiplicidad de factores que intervienen en el contexto del aula, y no en función del logro de un resultado final. En este sentido, las respuestas proporcionadas no resultan totalmente coherentes.

En cuanto al modo de transmitir los conocimientos científicos, la mayoría de los docentes $(80 \%)$ los presenta como conjeturables y problemáticos, destacando el proceso seguido en su construcción. Sin embargo, al establecer la relación entre concepción de conocimiento científico y modo de transmitirlo, se obtiene una asociación moderada y positiva, lo que permite afirmar que, en general, el modo de enseñar ciencia a los alumnos no resulta coherente con la concepción de conocimiento científico que poseen los docentes.

El aprendizaje de los conceptos científicos, para el $68 \%$ de los profesores, no consiste sólo en remplazar las ideas del alumno por otras científicamente aceptadas, sino en establecer una cierta conexión entre las teorías espontáneas del alumno y la que se trata de enseñar. Aprender ciencia consiste en modificar las propias teorías al tomar conciencia 
de que son erróneas, y no simplemente en asimilar los conceptos correctos de una disciplina.

Coherentemente con esta postura, para modificar las teorías del alumno, es necesario explorar sus conocimientos previos antes de iniciar un tema. Sin embargo, si bien los docentes llevan a cabo esta evaluación inicial, su objetivo no es conocer las concepciones de los alumnos para ayudarles a modificarlas, sino configurar un diagnóstico del grupo de clase. Esto permite inferir que los profesores no poseen una adecuada comprensión de la concepción que sustentan en relación con el aprendizaje de la ciencia.

Las estrategias didácticas a las que asignan prioridad en el aula resultan coherentes con su modo de concebir la enseñanza y el aprendizaje de las ciencias. Se hace énfasis en aquellas actividades de trabajo grupal en las que el alumno tiene una participación activa, tales como el contacto con la realidad, la discusión en pequeños grupos y la investigación sobre un problema. Estas estrategias utilizadas adecuadamente, configuran propuestas coherentes con la idea de construcción del conocimiento. Constituyen además una valiosa herramienta para que el alumno tome conciencia de que sus ideas espontáneas son incorrectas, no le sirven para explicar la realidad, y trate de modificarlas.

Se asigna en cambio escasa importancia a la exposición magistral del profesor y a la preparación y exposición de un tema por parte de los alumnos, estrategias que muchas veces llevan al enciclopedismo y al aprendizaje memorístico.

Con respecto al modo de evaluar, si bien su grado de asociación con la concepción epistemológica de los docentes es baja, existiría cierta tendencia a que quienes conciben el conocimiento como verdades absolutas y universales en el momento de evaluar traten de conocer el camino que recorrió el alumno para obtener la respuesta, y a que aquellos docentes que consideran el conocimiento como tentativo y provisional, evalúen en función del resultado que obtuvo el estudiante.

Para la indagación de las ideas previas de los alumnos se utilizan fundamentalmente las entrevistas individuales, técnica que, por su carácter interactivo y su flexibilidad, posibilita obtener información de gran riqueza. También se utilizan cuestionarios, instrumentos que permiten a los alumnos reflexionar sobre sus propias ideas en el transcurso del aprendizaje, y pruebas objetivas que serían las menos adecuadas para este propósito dado que limitan la posibilidad de explorar los procesos más complejos del aprendizaje.

\section{Referencias Bibliográficas}

Boido, G. "Historia de la ciencia y vida de la ciencia: algunas reflexiones educativas", en Revista de la enseñanza de la Física, No. 1, 1985.

Carretero, M. Construir y enseñar las ciencias experimentales. Buenos Aires: Paidós, 1996.

Castorina, J. A. y Palau, G. A. "Introducción a la traducción castellana", en Piaget, J., Apostel, L. y otros. Construcción y validación de las teorías científicas. Argentina: Paidos, 1994.

Díaz Barriga, A. Didáctica y currículum. Barcelona: Paidos, 1991.

Feyerabend, P. K. Contra el método. Barcelona. Ariel. 1975.

Gimeno Sacristán, J. La pedagogía por objetivos: su obsesión por la eficiencia. Madrid: Morata, 1995. 
Morata, 1995.

y Pérez Gómez, A. Comprender y transformar la enseñanza. Madrid:

Kuhn, S. T. La estructura de las revolucines científicas. Madrid. Fondo de Cultura Económica. 1978.

Mager, R. F. Formulación operativa de objetivos didácticos. Madrid: Marova, 1980.

Piaget, J. La epistemología genética. Madrid. Debate. 1986.

Pope y Scott. "Teacher's epistemology and practice", en Gimeno Sacristán, J. El currículum: una reflexión sobre la práctica. Madrid: Morata, 1984.

Popper, K. R. La lógica de la investigación científica. Madrid. Tecnos. 1980

Young, R. E. "The epistemic discourse of teachers: An etnographic study. Antropology and Education Quarterly", en Gimeno Sacristán, J. El currículum: una reflexión sobre la práctica. Madrid: Morata, 1981.

\section{ANEXO}

Estimado/a docente:

Este trabajo intenta explorar las actividades que desarrollan los docentes de ciencias naturales en sus prácticas cotidianas.

Se presenta a Ud. un conjunto de ítemes que deberá responder siguiendo las instrucciones correspondientes.

Nos interesa su opinión personal basada en la experiencia. Por favor, responda espontáneamente y sinceramente a todos los ítemes. Es indispensable su colaboración; de ella depende en alto grado la efectividad de nuestra tarea.

No es necesario que coloque su nombre y apellido, este trabajo es totalmente anónimo, pero sí le solicitamos algunos datos complementarios que son de nuestro interés.

Muchas gracias. 
Escuela:

Nivel educativo en el que se desempeña:

Curso:

Carrera:

Área:

Materia:

Antigüedad docente:

Sexo:

Edad:

Título que posee:

¿Ha asistido a algún curso de Historia y Filosofía de la Ciencia?:

Instrucciones:

Se presenta a Ud. un conjunto de ítemes con dos o más alternativas de respuesta.

En la mayoría de los casos, Ud. deberá seleccionar una alternativa encerrando la letra correspondiente con un círculo.

- $\quad$ En algunos ítemes, Ud. podrá optar por más de una alternativa, en cuyo caso el ítem lo señala explícitamente. importancia.

Muchas gracias por su colaboración.

1. ¿Cuál de las siguientes definiciones considera Ud. que refleja más adecuadamente su concepción de ciencia?

a) Es un producto compuesto por hechos, teorías, etc., que constituyen un cuerpo organizado de conocimientos.

b) Es el producto de un proceso de construcción de la realidad, sometido a influencias políticas, sociales, culturales e históricas.

2. Las teorías científicas están constituidas por:

a) Conocimientos que tienen carácter provisional y tentativo.

b) Conocimientos que expresan verdades absolutas y universales.

3. Las observaciones que realiza el científico en su actividad de búsqueda y descubrimiento:

a) Están condicionadas por sus marcos teóricos y conceptuales.

b) Están libres de teoría; son neutrales. 
4. El conocimiento científico se caracteriza por ser:

a) Una copia fiel de la realidad; el conocimiento obtenido se corresponde fielmente con la cosa conocida.

b) Una representación de la realidad, en cuya construcción intervienen factores que afectan la objetividad.

5. El conocimiento científico es el fruto de una ardua tarea llevada a cabo por:

a) Personas (genios) que trabajan aisladamente en sus laboratorios (torres de marfil) con el objetivo de poner a prueba sus hipótesis.

b) Una comunidad que trabaja en un contexto histórico y social con el propósito de generar nuevos conocimientos.

6. La ciencia puede ser considerada como:

a) Un proceso no lineal que presenta discontinuidades caracterizadas por el surgimiento de nuevos marcos conceptuales.

b) Un proceso acumulativo y lineal de conocimientos y verdades definitivas sobre la naturaleza.

7. Al diseñar una acción pedagógica eficaz, lo más importante es:

a) Partir de metas generales que orienten la acción sin preocuparse por predeterminar el resultado final.

b) Partir de objetivos claros y definidos que indiquen los resultados que se desean obtener en términos de conducta.

8. Su intervención en el aula consiste fundamentalmente en:

a) Aplicar de modo uniforme ciertas formas de actuar que se desprenden de teorías elaboradas por los científicos.

b) Actuar en forma autónoma, tomando sus propias decisiones en cada situación particular.

9. El objetivo fundamental de las clases de ciencias es:

a) Transmitir el corpus de conocimientos o verdades absolutas adquiridas por los científicos.

b) Presentar los conocimientos como conjeturables y problemáticos, destacando su evolución y los problemas que generaron su construcción.

10. El aprendizaje de la ciencia por parte de los alumnos se lleva a cabo:

a) Asimilando conceptos correctos desde el punto de vista de la disciplina.

b) Modificando sus propias teorías al tomar conciencia de que éstas no les sirven para explicar la realidad.

11. La estrategia a la que asigna prioridad en el proceso de enseñanza-aprendizaje es: (Asigne un orden de importancia colocando el número correspondiente delante de cada alternativa).

a) El contacto con la realidad.

b) La exposición magistral del profesor.

c) La investigación sobre el problema siguiendo los pasos del método científico.

d) La discusión en pequeños grupos.

e) La utilización de libros de textos.

f) Las experiencias de laboratorio.

g) La preparación y exposición de un tema por parte de los alumnos. 
h) Otros (especifique).

12. En el momento de evaluar, el interés se centra fundamentalmente:

a) En conocer el camino que recorrió el alumno para llegar a la respuesta.

b) En conocer el resultado o corrección de la respuesta dada por el alumno, para otorgar una calificación.

13. ¿Realiza Ud. algún tipo de evaluación para explorar los conocimientos de los alumnos antes de iniciar un tema?
a) Sí.

b) No.

14. Si su respuesta al ítem anterior es afirmativa, su principal objetivo es:

a) Conocer si las concepciones que posee el alumno son erróneas para ayudarle a modificarlas.

b) Motivar y despertar interés por la problemática.

c) Conocer el nivel de conocimiento respecto al tema, para no volver sobre lo enseñado.

d) Detectar problemas, dificultades y grado de compresión que poseen en relación con el tema para configurar un diagnóstico del grupo de clase.

15. Si su respuesta al ítem 13 fue afirmativa, para evaluar los conocimientos que poseen los alumnos al comenzar un tema, utiliza:

(Puede elegir más de una alternativa)

a) Entrevistas individuales con los alumnos.

b) Cuestionarios.

c) Pruebas objetivas.

d) Pruebas con ítemes que admiten varias posibilidades de solución.

e) Resolución de problemas sobre fenómenos científicos.

f) Otras (especifique). 